\title{
The Montreal Cognitive Assessment and the Mini-Mental State Examination as Screening Instruments for Cognitive Impairment: Item Analyses and Threshold Scores
}

\author{
Thesis submitted to the \\ University of Arizona College of Medicine - Phoenix \\ in partial fulfillment of the requirements for the degree of \\ Doctor of Medicine
}

Anne Mariam Damian

Class of 2012

Mentor: Sandra A. Jacobson, MD 


\section{Dedication}

I dedicate this thesis to my mentors in medical school, Dr. Sandra Jacobson and Dr. Charles Adler. Thank you for being my advocates throughout medical school, and for believing in me when all I had to offer was enthusiasm. 


\section{Acknowledgements}

I would like to acknowledge the co-authors of this manuscript as it appeared in Dementia and Geriatric Cognitive Disorders, as well as other contributors to this work:

Sandra A. Jacobson, MD, Banner Sun Health Research

Institute, Sun City, AZ

Joseph G. Hentz, MS, Mayo Clinic, Scottsdale, Arizona

Christine Belden, PsyD, Banner Sun Health Research Institute, Sun City, AZ

Holly A. Shill, MD, Banner Sun Health Research Institute, Sun City, AZ

Marwan N. Sabbagh, MD, Banner Sun Health Research Institute, Sun City, AZ

Linda Vedders, Banner Sun Health Research Institute, Sun City, AZ

John N. Caviness, MD, Mayo Clinic, Scottsdale, Arizona

Charles H. Adler, MD, PhD, Mayo Clinic, Scottsdale, Arizona 


\section{Abstract}

Objective: This study was performed to provide a detailed analysis of the MoCA versus the MMSE, including an item analysis and an examination of threshold scores appropriate for use in different clinical settings.

Methods: 135 subjects enrolled in a longitudinal clinicopathologic study were administered the MoCA and MMSE. Subjects were classified as cognitively impaired or cognitively normal based on neuropsychological testing and consensus conference diagnosis.

Results: 89 subjects were cognitively normal, 46 cognitively impaired (20 dementia, $26 \mathrm{MCI}$ ). ROC analysis showed that, for any threshold value selected for the MMSE to identify cognitive impairment, a MoCA value with better sensitivity and specificity could be identified. Recall performed best among individual items on the MMSE, and Orientation performed best on the MoCA. Overall, the best discrimination was obtained using a weighted combination of four items $(2 * \mathrm{MoCA}-$

Orientation + MMSE-Recall + MoCA-Language + 0.5* MoCAVisuospatial/Executive; AUC 0.94). A MoCA threshold score of 26 had a sensitivity of $98 \%$ and specificity of $52 \%$ for identifying cognitive 
impairment. A MoCA threshold score of 21 had a sensitivity of $57 \%$ and specificity of $96 \%$.

Conclusions: The MoCA was superior to the MMSE in detecting cognitive impairment. Individual domains on the MoCA and MMSE made substantially different contributions to each instrument's sensitivity, and a weighted subset of items from both instruments performed best in detecting cognitive impairment. A lower MoCA threshold score may be appropriate in a population with a higher prevalence of cognitive impairment such as a memory clinic.

Glossary: AUC = area under the curve; BSHRI = Banner Sun Health Research Institute; $\mathbf{M C I}=$ mild cognitive impairment; $\mathbf{M M S E}=$ Mini Mental State Examination; MoCA = Montreal Cognitive Assessment. 


\section{Table of Contents}

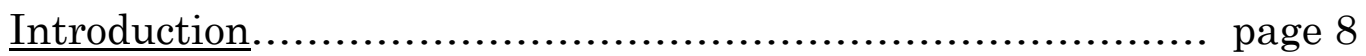

Research Materials and Methods......................................page 11

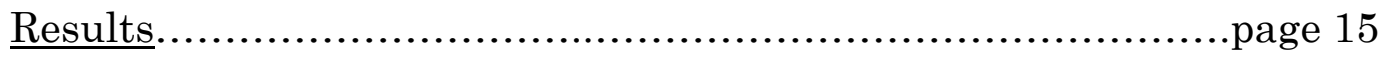

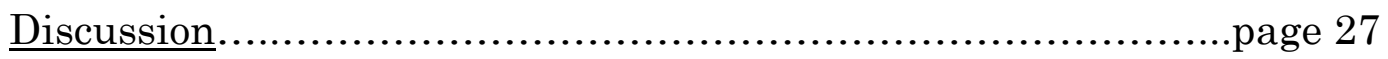

Future Directions............................................... page 30

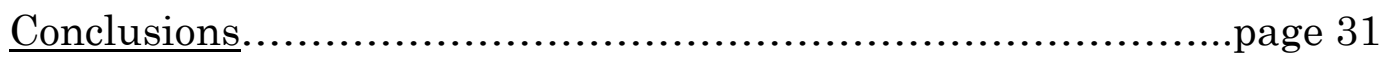

References...................................................... page 32 


\section{List of Figures and Tables}

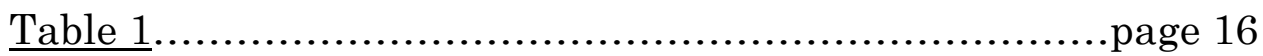

"Characteristics of cognitively impaired versus cognitively normal subjects"

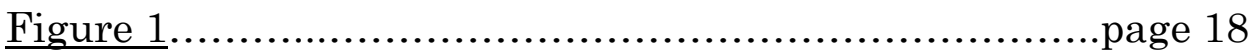

"ROC analysis: MoCA versus MMSE"

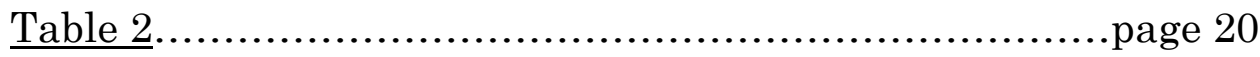

"Correlation of performance on individual MMSE items and cognitive impairment"

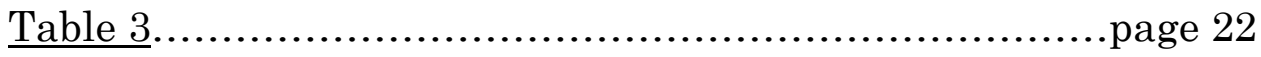

"Correlation of performance on individual MoCA items and cognitive impairment"

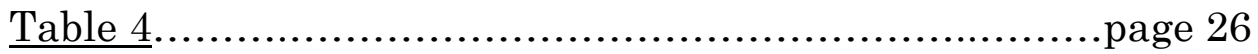

"MoCA versus MMSE: sensitivity, specificity, and predictive values" 


\section{Introduction}

The Mini-Mental State Examination (MMSE) ${ }^{1}$ is the most widely used cognitive screening instrument worldwide, available in a multitude of translations, and validated in as many clinical populations. The original mini mental state was designed to assess dementia due to affective disorders such as depression, as well as schizophrenia and personality disorders (Folstein et. al, 1975). Most clinicians in the field would agree that the MMSE has been largely removed from this context. The instrument has proven to be relatively insensitive to conditions associated with frontal-executive and subcortical dysfunction, and to milder forms of cognitive impairment. The MMSE has a maximum score of 30 and has normative data corrected for age and level of education. In spite of its obvious utility, the instrument has proven to be relatively insensitive to conditions associated with frontal-executive and subcortical dysfunction, and to milder forms of cognitive impairment. ${ }^{2}$ Numerous attempts have been made to develop and popularize an alternative to the MMSE..$^{3-5}$ The Montreal Cognitive Assessment (MoCA) is one effort that appears to have captured the attention needed to enter the competitive arena 
which the MMSE has dominated. Developed and introduced by Nasreddine and colleagues in $2005,{ }^{6}$ the MoCA has been put forth as an instrument with superior sensitivity to the MMSE, sufficiently sensitive to detect mild cognitive impairment, and broad-based enough to detect both Alzheimer and non-Alzheimer dementia, at least for screening purposes. ${ }^{7}$ The MoCA is intended as a screening instrument for cognitive function, which may be administered by a range of health care providers in a variety of settings, from a primary care setting to a specialized dementia clinic. It is important to clarify that this tool is not intended as a diagnostic instrument, with threshold scores identifying the presence of disease, but rather as screening tools designed to indicate the need for further work-up. Both the MoCA and the MMSE are rapid cognitive screening instruments, designed to evaluate the cognitive domains of memory, language, executive function, visuospatial function, attention and calculation. The MoCA aimed to address concerns following four decades of experience with the MMSE- namely to create an instrument that better assessed executive function, included a more difficult test of memory and included a more comprehensive language assessment. With these more challenging tasks the MoCA also aims to address the prominent ceiling 
effect which plagued the MMSE, particularly in patients with higher levels of education. Another advantage of this newer instrument is simply that it is not hindered by the bias of the practice effect as the MMSE does, a consequence of over 40 years of its widespread use.

The MoCA has now been studied in a number of different clinical populations, ${ }^{2,8-15}$ although not all studies employed neuropsychological testing as a reference standard. Research in using the MoCA longitudinally has indicated that in patients diagnosed with MCI, the MoCA helps to identify those at risk of developing dementia at 6 month follow up, although this data did not include neuropsychological testing. ${ }^{7}$ Most studies used a MoCA threshold score of 26 , recommended by the original MoCA validation study as yielding the best balance of sensitivity and specificity for the MCI and $\mathrm{AD}$ groups, however, data provided by Luis and colleagues suggested that a MoCA threshold score of 23 might be superior. ${ }^{6,16}$ The current study was performed to provide a detailed analysis of the MoCA versus the MMSE, including an item analysis and an examination of threshold scores in determining cognitive impairment appropriate for use in different clinical settings. 


\section{Research Materials and Methods}

Informed Consent: Written informed consent, approved by the Banner Sun Health Research Institute (BSHRI) Institutional Review Board, was obtained from all subjects through the Brain and Body Donation Program, a brain registry for neurodegenerative diseases.

Study Design: The study was conducted within the BSHRI Brain and Body Donation Program, in which participants undergo an annual standardized evaluation that includes physical and neurological examination, movement specialist evaluation, and standardized neuropsychological testing. Details of the evaluation have been described elsewhere. ${ }^{17,} 18$ A nearly consecutive sample of subjects were administered the MoCA by a single physician (SAJ); external time constraints prohibited exact consecutive sampling. The MMSE was performed by a study nurse. Demographic information collected on all subjects included date of birth, gender, and years of education. For most subjects, MoCA and MMSE testing were completed on the same day. Subjects also underwent an evaluation by a movement disorders specialist and the following neuropsychological tests: Mattis Dementia

Rating Scale-2, WMS-R Logical Memory, Rey Auditory Verbal 
Learning Test, Brief Visual Memory Test-Revised, Facial Recognition Test, Token Test, Category Fluency (animals and vegetables), Controlled Oral Word Association Test (CFL), Boston Naming Test-2, WMS-R Digit Span, Trail Making Tests A and B, Stroop, WAIS-III Similarities, WAIS-R Digit Symbol, Clock Drawing Test , Judgment of Line Orientation, WAIS-III Block Design, WAIS-III Vocabulary, WAISIII Information, and the WRAT-3 Reading subtest. Additionally, WAIS-III Information and Vocabulary and WRAT-3 Reading provided estimates of premorbid abilities. Neuropsychological testing was performed as closely as possible in time to the neurological and movement evaluations. The neuropsychologist determined the designation of "cognitively normal" or "cognitively impaired" based on neuropsychological test results. At a consensus conference, the neurological, movement, and cognitive diagnoses were established.

Subjects: The study group consisted of 135 subjects, 89 cognitively normal, and 46 cognitively impaired. Specific cognitive diagnoses were as follows: amnestic MCI (n=13), multi-domain amnestic MCI (7), nonamnestic single domain MCI (5), non-amnestic multi-domain MCI (1), probable $\mathrm{AD}(2)$, possible $\mathrm{AD}$ (5), dementia with Lewy bodies (1), Parkinson's disease dementia (4), vascular dementia (3), mixed 
vascular dementia (1), cognitive impairment due to medication or medical illness (3), and cognitive impairment of undetermined etiology (1 subject). In this sample, 37 patients were diagnosed with probable PD, 24 of whom were cognitively normal, and 13 cognitively impaired (9 PD-MCI, 4 PD-D).

Statistical Analysis: The prevalence and mean of characteristics in the cognitively impaired group were compared to that of the cognitively normal group using the Pearson chi-square test or two-sample $t$ test. The diagnostic accuracy of each screening instrument (MoCA and MMSE) was assessed by calculating the area under the receiver operating characteristics curve (AUC), which represents the average sensitivity for all possible values of specificity. Diagnostic accuracy was also assessed by calculating the sensitivity and specificity for the threshold that yielded the highest Youden index (Youden index $=$ sensitivity - (1 - specificity)). The threshold with the highest Youden index has the highest difference in the proportion of subjects with a positive test result between the impaired and normal groups. The relationship between cognitive impairment and individual items from the MoCA and MMSE was assessed using logistic regression. An abbreviated cognitive assessment instrument was created using 
multiple logistic regression modeling in which a subset of items from the MoCA and MMSE was selected by the Forward Selection method. Forward Selection was used because the number of potential items was large in comparison to the number of subjects with impairment. The paired difference in AUC between the MoCA and MMSE was assessed using the percentile bootstrap method. The predictive value was calculated using Bayes' rule because the sample prevalence of cognitive impairment is higher than the population prevalence due to the way subjects are recruited in the Brain and Body Donation Program. 


\section{Results}

The MoCA and MMSE were administered between 24 November 2008 and 18 January 2010 to 46 subjects who were cognitively impaired (26 with MCI and 20 with dementia) and 89 subjects who were cognitively normal. Age of subjects ranged from 46 to 100 years. Education ranged from 10 to 23 years. The percentage of women was lower in the impaired group than in the normal group. Mean age, mean years of education, prevalence of subjects with less than 12 years of education, and prevalence of movement disorders did not differ substantially between the two groups. Group comparisons are shown in Table 1. 
Table 1: Characteristics of cognitively impaired versus cognitively normal subjects

\begin{tabular}{|c|c|c|c|c|c|c|}
\hline & $\begin{array}{l}\text { Cognitively } \\
\text { Impaired } \\
(\mathrm{n}=46)\end{array}$ & $\begin{array}{l}\text { Cognitively } \\
\text { Normal } \\
(\mathrm{n}=89)\end{array}$ & $\bar{\Delta}$ & $95 \% \mathrm{CI}$ & $P^{\mathrm{a}}$ & $\begin{array}{l}\text { AUC } \\
\mathrm{b}\end{array}$ \\
\hline Female & $13(28 \%)$ & $58(65 \%)$ & -0.37 & $\begin{array}{l}-0.53 \text { to }- \\
0.21\end{array}$ & $<.001$ & 0.68 \\
\hline Age (y) & $79.4(7.8)$ & $77.7(9.5)$ & 1.7 & -1.6 to 4.9 & .31 & 0.54 \\
\hline Education (y) & $15.5(2.6)$ & $15.2(2.7)$ & 0.2 & -0.7 to 1.2 & .65 & 0.52 \\
\hline Education $<12 \mathrm{y}$ & $1(2 \%)$ & $2(2 \%)$ & 0.00 & $\begin{array}{l}-0.05 \text { to } \\
0.05\end{array}$ & 0.98 & 0.50 \\
\hline Parkinson's disease $^{\mathrm{c}}$ & $13 / 43(30 \%)$ & $20 / 88(23 \%)$ & 0.08 & $\begin{array}{l}-0.09 \text { to } \\
0.24\end{array}$ & .35 & 0.54 \\
\hline Any Movement Disorder ${ }^{\mathrm{c}}$ & $32 / 43(74 \%)$ & $58 / 88(66 \%)$ & 0.09 & $\begin{array}{l}-0.08 \text { to } \\
0.25\end{array}$ & .32 & 0.54 \\
\hline MMSE & $25.3(3.3)$ & $28.5(1.6)$ & -3.2 & -4.0 to -2.4 & $<.001$ & 0.82 \\
\hline $\mathrm{MoCA}$ & $19.0(4.4)$ & $25.3(2.8)$ & -6.4 & -7.6 to -5.2 & $<.001$ & 0.90 \\
\hline Orientation & $4.3(1.4)$ & $5.82(0.44)$ & $\begin{array}{ll}-1.5 \\
\end{array}$ & -1.8 to -1.2 & $<.001$ & 0.84 \\
\hline $2^{*}$ Orientation + Recall & $10.3(3.3)$ & $14.3(1.2)$ & -4.0 & -4.8 to -3.3 & $<.001$ & 0.91 \\
\hline $\begin{array}{l}2^{*} \text { Orientation }+ \text { Recall }+ \\
\text { Language }+ \\
0.5^{*} \text { Visuospatial }\end{array}$ & $13.7(3.7)$ & $19.0(1.6)$ & $\begin{array}{c}-5.3 \\
\end{array}$ & -6.2 to -4.4 & $<.001$ & 0.94 \\
\hline
\end{tabular}

a Pearson chi-square test or two-sample $t$ test.

b Area under the receiver operating characteristics curve.

c Four subjects did not have a movement disorder diagnosis from a movement specialist. 
MMSE scores ranged from 14 to 30, and MoCA scores ranged from 7 to 30 (with maximum possible score for both tests $=30$ ). Between the impaired and normal groups, the mean MoCA scores differed by 1.9 standard deviations, and the mean MMSE scores differed by 1.4 standard deviations. The AUC for the MoCA was 0.90 versus 0.82 for the MMSE $(P=.04)$. The receiver operating characteristics curves (ROC) are shown in Figure 1, as a measure of sensitivity and specificity of these tests in identifying cognitive impairment. The average sensitivity over all possible values of specificity was 8 percentage points higher for the MoCA than for the MMSE. Visually, it can be observed that the ROC curve for the MMSE was entirely contained by the curve for the MoCA, demonstrating that, for any threshold selected for the MMSE, there was a threshold for the MoCA that yielded both higher sensitivity and higher specificity. 
Figure 1: ROC analysis: MoCA versus MMSE.

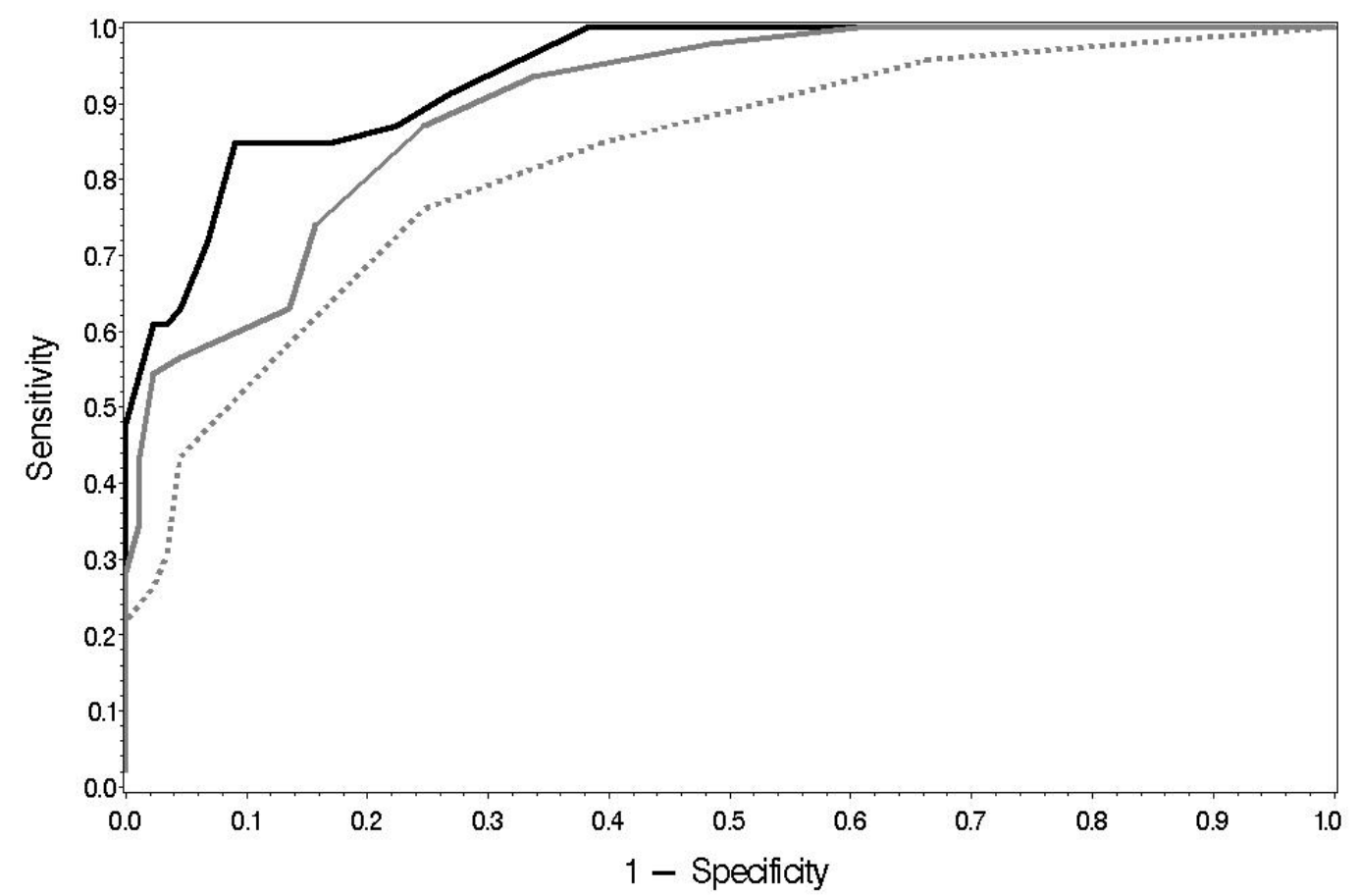

Receiver operating characteristics of the MoCA (solid gray)- AUC: 0.90, MMSE (dashed gray)- AUC: 0.82, and an abbreviated instrument with items weighted (black) for identifying subjects with cognitive impairment $\left(2^{*}\right.$ Orientation + Recall + Language $+0.5^{*}$ Visuospatial)0.94 . 
The correlations of individual MMSE task items with cognitive impairment are shown in Table 2, and individual MoCA task items with cognitive impairment in Table 3 . As shown in Table 1 , the Orientation item from the MoCA ( $\mathrm{AUC}=0.84)$ performed as well as the entire MMSE (AUC=0.82). A weighted combination of the best item from the MoCA (Orientation) and the best item from the MMSE (Recall) (combined AUC=0.91) performed as well as the MoCA total score (AUC=0.90). The best performance overall was obtained from a weighted combination of four items from the MoCA and MMSE $\left(2^{*}\right.$ MoCA-Orientation + MMSE-Recall + MoCA-Language + 0.5*MoCAVisuospatial-Executive) (AUC=0.94). If this four-item test were used in a population with a $20 \%$ prevalence of cognitive impairment (Table 4 ), $70 \%$ of subjects with a score less than 17 would have cognitive impairment versus only $4 \%$ of subjects with a score of 17 or more. At this same prevalence of cognitive impairment, increasing the threshold performance score to 19 would slightly improve sensitivity, at the expense of a large drop in specificity. 
Table 2: Association of performance on individual MMSE items and cognitive impairment

\begin{tabular}{|c|c|c|c|c|c|c|c|c|c|}
\hline & OR & $\begin{array}{l}95 \% \\
\text { CI }\end{array}$ & $\boldsymbol{P}^{\mathrm{a}}$ & AUC & & OR & $\begin{array}{l}95 \% \\
\text { CI }\end{array}$ & $\boldsymbol{P}^{\mathrm{a}}$ & AUC \\
\hline Time & 3.3 & $\begin{array}{l}1.92 \\
\text { to } 5.6\end{array}$ & $<.001$ & 0.72 & Attention & 1.91 & $\begin{array}{l}1.31 \\
\text { to } \\
2.8\end{array}$ & .001 & 0.63 \\
\hline Year & 8.4 & $\begin{array}{l}0.91 \\
\text { to } 77\end{array}$ & .06 & 0.54 & $\underline{\text { Recall }}$ & 3.7 & $\begin{array}{l}2.2 \\
\text { to } \\
6.0\end{array}$ & $<.001$ & 0.77 \\
\hline Season & 2.5 & $\begin{array}{l}0.88 \\
\text { to } 6.9\end{array}$ & .09 & 0.55 & Apple & 15 & $\begin{array}{l}3.3 \\
\text { to } \\
72\end{array}$ & $<.001$ & 0.62 \\
\hline Month & 5.3 & $\begin{array}{l}0.99 \\
\text { to } 29\end{array}$ & .05 & 0.54 & Penny & 9.1 & $\begin{array}{l}3.9 \\
\text { to } \\
21\end{array}$ & $<.001$ & 0.73 \\
\hline Day & 8.0 & $\begin{array}{l}2.1 \text { to } \\
31\end{array}$ & .003 & 0.59 & Table & 4.6 & $\begin{array}{l}2.1 \\
\text { to } \\
10\end{array}$ & $<.001$ & 0.66 \\
\hline Date & 3.8 & $\begin{array}{l}1.66 \\
\text { to } 8.5\end{array}$ & .002 & 0.63 & Naming & $\mathrm{NA}$ & NA & $\mathrm{NA}$ & NA \\
\hline$\underline{\text { Place }}$ & 1.77 & $\begin{array}{l}1.09 \\
\text { to } 2.9\end{array}$ & .02 & 0.58 & Pencil & NA & NA & NA & NA \\
\hline State & $\mathrm{NA}$ & NA & NA & NA & Watch & NA & NA & NA & NA \\
\hline Country & 6.5 & $\begin{array}{l}1.26 \\
\text { to } 34\end{array}$ & .03 & 0.55 & Repetition & 1.42 & $\begin{array}{l}0.56 \\
\text { to } \\
3.6\end{array}$ & .46 & 0.52 \\
\hline City & 1.92 & $\begin{array}{l}0.72 \\
\text { to } 5.1\end{array}$ & .19 & 0.54 & Comprehension & 2.0 & $\begin{array}{l}0.81 \\
\text { to } \\
5.2\end{array}$ & .13 & 0.55 \\
\hline Building & 2.0 & $\begin{array}{l}0.81 \\
\text { to } 5.0\end{array}$ & .13 & 0.55 & Hand & 2.0 & $\begin{array}{l}0.56 \\
\text { to } \\
7.5\end{array}$ & .28 & 0.53 \\
\hline
\end{tabular}




\begin{tabular}{|c|c|c|c|c|c|c|c|c|c|}
\hline Floor & NA & $\mathrm{NA}$ & .99 & 0.51 & Fold & 1.96 & $\begin{array}{l}0.12 \\
\text { to } \\
32\end{array}$ & .64 & 0.50 \\
\hline Registration & 4.0 & $\begin{array}{l}0.35 \\
\text { to } 45\end{array}$ & .26 & 0.52 & Floor & 3.0 & $\begin{array}{l}0.49 \\
\text { to } \\
19\end{array}$ & .23 & 0.52 \\
\hline Apple & NA & $\mathrm{NA}$ & .99 & 0.51 & Reading & NA & NA & .99 & 0.51 \\
\hline Penny & NA & NA & NA & $\mathrm{NA}$ & Writing & NA & NA & NA & $\mathrm{NA}$ \\
\hline Table & NA & $\mathrm{NA}$ & .98 & 0.52 & Drawing & 3.4 & $\begin{array}{l}1.42 \\
\text { to } \\
8.3\end{array}$ & .006 & 0.60 \\
\hline
\end{tabular}

a Logistic regression.

Underlined items refer to MMSE category headings 
Table 3: Association of performance on individual MoCA items and cognitive impairment

\begin{tabular}{|c|c|c|c|c|c|c|c|c|c|}
\hline & OR & $95 \%$ CI & $\overline{P^{a}}$ & AUC & & OR & $95 \%$ CI & $\overline{P^{a}}$ & AUC \\
\hline Visuospatial & 2.5 & $\begin{array}{c}1.64 \text { to } \\
3.7\end{array}$ & $<.001$ & 0.72 & Fluency "F" & 3.5 & $\begin{array}{c}1.58 \text { to } \\
7.8\end{array}$ & .002 & 0.63 \\
\hline Mini Trails B & 5.4 & $\begin{array}{c}2.1 \text { to } \\
14\end{array}$ & $<.001$ & 0.63 & Abstraction & 2.5 & $\begin{array}{c}1.28 \text { to } \\
4.9\end{array}$ & .007 & 0.62 \\
\hline Cube & 3.0 & $\begin{array}{c}1.43 \text { to } \\
6.2\end{array}$ & .003 & 0.63 & Train-Bike & 3.5 & $\begin{array}{c}1.37 \text { to } \\
9.0\end{array}$ & .009 & 0.59 \\
\hline Clock & 3.0 & $\begin{array}{c}1.59 \text { to } \\
5.7\end{array}$ & .001 & 0.64 & Watch-Ruler & 1.97 & $\begin{array}{c}0.77 \text { to } \\
5.1\end{array}$ & .16 & 0.55 \\
\hline Naming & 0.89 & $\begin{array}{c}0.33 \text { to } \\
2.4\end{array}$ & .82 & 0.50 & $\begin{array}{l}\text { Delayed } \\
\text { Recall }\end{array}$ & 2.5 & $\begin{array}{c}1.81 \text { to } \\
3.5\end{array}$ & $<.001$ & 0.82 \\
\hline Lion & 0.97 & $\begin{array}{c}0.08 \text { to } \\
11\end{array}$ & .98 & 0.50 & Face & 12 & $\begin{array}{c}4.7 \text { to } \\
33\end{array}$ & $<.001$ & 0.76 \\
\hline Rhinoceros & 0.86 & $\begin{array}{c}0.28 \text { to } \\
2.7\end{array}$ & .80 & 0.51 & Velvet & 9.8 & $\begin{array}{c}4.1 \text { to } \\
24\end{array}$ & $<.001$ & 0.75 \\
\hline Camel & NA & $\mathrm{NA}$ & NA & NA & Church & 2.9 & $\begin{array}{c}1.26 \text { to } \\
6.8\end{array}$ & .01 & 0.61 \\
\hline Attention & 1.91 & $\begin{array}{c}1.36 \text { to } \\
2.7\end{array}$ & $<.001$ & 0.68 & Daisy & 12 & $\begin{array}{c}2.8 \text { to } \\
54\end{array}$ & .001 & 0.66 \\
\hline Digits & 3.7 & $\begin{array}{c}1.62 \text { to } \\
8.6\end{array}$ & .002 & 0.62 & Red & 6.0 & $\begin{array}{c}2.4 \text { to } \\
15\end{array}$ & $<.001$ & 0.68 \\
\hline Forward & 2.0 & $\begin{array}{c}0.56 \text { to } \\
7.5\end{array}$ & .28 & 0.53 & Orientation & 7.7 & $\begin{array}{c}3.8 \text { to } \\
16\end{array}$ & $<.001$ & 0.84 \\
\hline Reverse & 5.4 & $\begin{array}{c}1.91 \text { to } \\
16\end{array}$ & .002 & 0.61 & Date & 15 & $\begin{array}{c}5.8 \text { to } \\
40\end{array}$ & $<.001$ & 0.74 \\
\hline Letter A & 2.9 & $\begin{array}{c}1.28 \text { to } \\
6.5\end{array}$ & .01 & 0.60 & Month & $\mathrm{NA}$ & NA & .97 & 0.59 \\
\hline
\end{tabular}




\begin{tabular}{|c|c|c|c|c|c|c|c|c|c|}
\hline Serial 7s & 1.79 & $\begin{array}{c}1.18 \text { to } \\
2.7\end{array}$ & .006 & 0.63 & Year & 19 & $\begin{array}{c}2.2 \text { to } \\
153\end{array}$ & .006 & 0.58 \\
\hline Language & 3.0 & $\begin{array}{c}1.88 \text { to } \\
4.9\end{array}$ & $<.001$ & 0.74 & Day & $\mathrm{NA}$ & NA & .97 & .60 \\
\hline Repetition & 3.1 & $\begin{array}{c}1.76 \text { to } \\
5.5\end{array}$ & $<.001$ & 0.70 & Place & 11 & $\begin{array}{c}3.9 \text { to } \\
29\end{array}$ & $<.001$ & 0.68 \\
\hline John & 3.6 & $\begin{array}{c}1.34 \text { to } \\
9.5\end{array}$ & .01 & 0.58 & City & 6.5 & $\begin{array}{c}1.26 \text { to } \\
34\end{array}$ & .03 & 0.55 \\
\hline Cat & 4.3 & $\begin{array}{c}2.0 \text { to } \\
9.2\end{array}$ & $<.001$ & 0.67 & & & & & \\
\hline
\end{tabular}

a Logistic regression 
Previous studies 11, 16 have used a threshold ("cut-off") score of 25 for the MMSE and 26 for the MoCA to define cognitive normalcy. Using these values, the MoCA has higher sensitivity but lower specificity than the MMSE (Table 4). A MoCA threshold score of 26 has a sensitivity of $98 \%$ and specificity of $52 \%$ for identifying cognitive impairment. In a population with $20 \%$ prevalence of cognitive impairment, a threshold score of 26 would have $34 \%$ positive predictive value and $99 \%$ negative predictive value. As is always the case with predictive values, and as Table 4 shows, the predictive value of the MoCA versus the MMSE changes with the prior probability of cognitive impairment in the population studied, and can be manipulated by changing the threshold value. For example, our data set showed that a threshold score of 21 for the MoCA had the same specificity as the MMSE with a threshold of 25 , and a substantially greater sensitivity. The Youden index, a single statistic that captures the performance of a diagnostic test, is defined as sensitivity + specificity -1. A threshold of 28 yielded the greatest Youden index for the MMSE, and a threshold of 24 yielded the greatest Youden index for the MoCA. At these thresholds, the observed sensitivity for the MoCA was $87 \%$ versus $76 \%$ for the MMSE, while both tests had a specificity 
of $75 \%$. If these instruments were used in a population with a $20 \%$ prevalence of cognitive impairment, a MoCA threshold of 24 (rather than 26) would reduce the percentage of false positives by $18 \%$ while only increasing the percentage of false negatives by $2 \%$. 
Table 4: MoCA versus MMSE: sensitivity, specificity, and predictive values

\begin{tabular}{|c|c|c|c|c|c|c|c|c|}
\hline & & & \multicolumn{6}{|c|}{ Prevalence of Dementia } \\
\hline & & & \multicolumn{2}{|l|}{$15 \%$} & \multicolumn{2}{|l|}{$20 \%$} & \multicolumn{2}{|l|}{$25 \%$} \\
\hline & Sensitivity & Specificity & PPV & NPV & PPV & NPV & PPV & NPV \\
\hline MMSE $<25^{\text {a }}$ & $30 \%$ & $97 \%$ & $61 \%$ & $89 \%$ & $69 \%$ & $85 \%$ & $75 \%$ & $81 \%$ \\
\hline $\mathrm{MoCA}<26^{\mathrm{a}}$ & $98 \%$ & $52 \%$ & $26 \%$ & $99 \%$ & $34 \%$ & $99 \%$ & $40 \%$ & $99 \%$ \\
\hline $\mathrm{MoCA}<21^{\mathrm{b}}$ & $57 \%$ & $96 \%$ & $69 \%$ & $93 \%$ & $76 \%$ & $90 \%$ & $81 \%$ & $87 \%$ \\
\hline MMSE $<28^{c}$ & $76 \%$ & $75 \%$ & $35 \%$ & $95 \%$ & $43 \%$ & $93 \%$ & $51 \%$ & $90 \%$ \\
\hline $\mathrm{MoCA}<24^{\mathrm{c}}$ & $87 \%$ & $75 \%$ & $38 \%$ & $97 \%$ & $47 \%$ & $96 \%$ & $54 \%$ & $95 \%$ \\
\hline $\begin{array}{l}\text { Orientation }< \\
6^{\mathrm{c}}\end{array}$ & $78 \%$ & $84 \%$ & $47 \%$ & $96 \%$ & $55 \%$ & $94 \%$ & $62 \%$ & $92 \%$ \\
\hline $\begin{array}{l}2^{*} \text { Orientation } \\
+ \text { Recall }<14^{\mathrm{c}}\end{array}$ & $89 \%$ & $81 \%$ & $45 \%$ & $98 \%$ & $54 \%$ & $97 \%$ & $61 \%$ & $96 \%$ \\
\hline $\begin{array}{l}2^{*} \text { Orientation } \\
+ \text { Recall }+ \\
\text { Language }+ \\
0.5^{*} \text { VS-Exec }< \\
17^{c}\end{array}$ & $85 \%$ & $91 \%$ & $62 \%$ & $97 \%$ & $70 \%$ & $96 \%$ & $76 \%$ & $95 \%$ \\
\hline $\begin{array}{l}2^{*} \text { Orientation } \\
+ \text { Recall }+ \\
\text { Language }+ \\
0.5^{*} \text { VS-Exec < } \\
19^{\mathrm{d}}\end{array}$ & $99 \%$ & $62 \%$ & $31 \%$ & $99 \%$ & $39 \%$ & $99 \%$ & $46 \%$ & $99 \%$ \\
\hline
\end{tabular}

a Threshold recommended in literature.

b Threshold to match sensitivity of MMSE $<25$.

c Threshold for maximum Youden index.

d Threshold to favor sensitivity.

PPV=Positive predictive value.

NPV=Negative predictive value.

Prevalence of Dementia 


\section{Discussion}

In this study of a well-characterized population of 46 cognitively impaired and 89 cognitively normal subjects administered the MoCA and the MMSE, the MoCA proved to be superior in both sensitivity and specificity in the identification of cognitive impairment, when applied against the gold standard of neuropsychological testing.

The study confirmed that the MoCA tasks are not all of equal predictive value. Our experience with the MoCA is that animal picture naming is a relatively poor discriminator because of a ceiling effect (the item is "too easy"), and 5-word recall is a poor discriminator because of a floor effect (the item is "too hard"). The present analysis suggests that a slightly abbreviated hybrid scale consisting of four items identified from the MMSE and MoCA might in fact have predictive value that is superior to both scales. These items include Orientation, Language, and Visuospatial/Executive items from the MoCA, and 3word recall from the MMSE.

The ROC analysis of the MoCA versus the MMSE showed that the recommended threshold score for the MoCA (26) favors sensitivity at the expense of specificity, indicating that it is more appropriate for 
screening purposes. The goal of this instrument as a screening tool is simply to filter which patients warrant proceeding to time intensive and costly neuropsychological testing, and thus an instrument which favors sensitivity and hence can rule out disease is most valuable. On the other hand, for a population with a high prior probability of cognitive impairment such as a memory disorders clinic, a threshold score of 24 might be more appropriate. It is interesting to note that, for the MMSE, the recommended threshold score of 25 appears to have favored specificity at the expense of sensitivity, and it is precisely the lack of sensitivity for which the MMSE has been faulted.

Weaknesses of the study include the relative homogeneity of the sample demographics (Caucasian, well educated retirees), small numbers of cases with individual subtypes of cognitive impairment, and a high proportion of cases with primary memory impairment. The strengths of this study include the complete characterization of the subject sample, employing not only standardized physical and neurological examinations, but also standardized movement evaluations and neuropsychological testing. In addition, all MoCA evaluations were administered by a single physician. The designation of "cognitively impaired" versus "cognitively normal" was made on the 
basis of objective findings from neuropsychological testing. A spectrum of cognitive impairment was seen, from what appears to be early MCI to advanced dementia. However, the sample size of individual subtypes of dementia were not sufficient to draw conclusions about particular clinical entities within our group of patients deemed to be "cognitively impaired."

Our analysis suggests that certain elements of the basic cognitive screening evaluation are highly predictive of cognitive impairment as determined by neuropsychological testing. Different threshold scores used to indicate cognitive impairment may apply to populations with a different prior probability of cognitive decline. 


\section{Future Directions}

This study focused on subjects with Alzheimer's disease versus cognitively normal control subjects. The original sample included only 4 patients with Parkinson's disease dementia, 1 patient with Dementia with Lewy bodies, and 3 patients with vascular dementia. A natural extension of this study is to attempt to determine whether the MoCA is indeed more sensitive for various sub-types of dementia. Since the original project was conducted, approximately 300 additional MoCAs have been collected from patients enrolled in the BSHRI Brain and Body Donation Program. This data is currently being compiled and analyzed, with the idea of validating the MoCA for use in screening for Parkinson's disease dementia and mild cognitive impairment. 


\section{Conclusions}

This study found that the MoCA was superior in both sensitivity and specificity to the MMSE in detecting cognitive impairment, across all threshold ("cut-off") scores. This suggests that this instrument is more appropriate as a screening tool for patients with cognitive impairment than the MMSE, and may be especially helpful in a primary care setting without access to full neuropsychological testing. We confirmed a clinical suspicion that individual domains of the MoCA and MMSE made substantially different contributions to each instrument's sensitivity. A weighted subset of items from both instruments performed best in detecting cognitive impairment. This data therefore suggests the possibility of an abbreviated tool, which may address the time limitation associated with the fact that the MoCA is a slightly longer task to administer. Further study is required to determine whether the MoCA is indeed a more sensitive cognitive assessment tool for all subtypes of dementia. 


\section{References}

1. Folstein MF, Folstein SE, McHugh PR. "Mini-mental state". A practical method for grading the cognitive state of patients for the clinician. J Psychiatr Res. 1975;12:189-198.

2. Pendlebury ST, Cuthbertson FC, Welch SJ, Mehta Z, Rothwell PM. Underestimation of cognitive impairment by mini-mental state examination versus the montreal cognitive assessment in patients with transient ischemic attack and stroke: a population-based study. Stroke. 2010;41:1290-1293.

3. Borson S, Scanlan J, Brush M, Vitaliano P, Dokmak A. The minicog: a cognitive 'vital signs' measure for dementia screening in multilingual elderly. Int J Geriatr Psychiatry.2000;15:1021-1027.

4. Mathuranath PS, Nestor PJ, Berrios GE, Rakowicz W, Hodges JR. A brief cognitive test battery to differentiate Alzheimer's disease and frontotemporal dementia. Neurology. 2000;55:1613-1620.

5. Buschke H, Kuslansky G, Katz M, et al. Screening for dementia with the memory impairment screen. Neurology. 1999;52:231-238. 
6. Nasreddine ZS, Phillips NA, Bedirian V, et al. The Montreal Cognitive Assessment, MoCA: a brief screening tool for mild cognitive impairment. J Am Geriatr Soc. 2005;53:695-699.

7. Smith T, Gildeh N, Holmes C. The Montreal Cognitive Assessment: validity and utility in a memory clinic setting. Can J Psychiatry. 2007;52:329-332.

8. Gill DJ, Freshman A, Blender JA, Ravina B. The Montreal cognitive assessment as a screening tool for cognitive impairment in Parkinson's disease. Mov Disord. 2008;23:1043-1046.

9. Zadikoff C, Fox SH, Tang-Wai DF, et al. A comparison of the mini mental state exam to the Montreal cognitive assessment in identifying cognitive deficits in Parkinson's disease. Mov Disord. 2008;23:297-299. 10. Hoops S, Nazem S, Siderowf AD, et al. Validity of the MoCA and MMSE in the detection of MCI and dementia in Parkinson disease. Neurology. 2009;73:1738-1745.

11. Nazem S, Siderowf AD, Duda JE, et al. Montreal cognitive assessment performance in patients with Parkinson's disease with "normal" global cognition according to mini-mental state examination score. J Am Geriatr Soc. 2009;57:304-308. 
12. Videnovic A, Bernard B, Fan W, Jaglin J, Leurgans S, Shannon KM. The Montreal Cognitive Assessment as a screening tool for cognitive dysfunction in Huntington's disease. Mov Disord. 2010;25:401-404.

13. Gagnon JF, Postuma RB, Joncas S, Desjardins C, Latreille V. The Montreal Cognitive Assessment: a screening tool for mild cognitive impairment in REM sleep behavior disorder. Mov Disord. 2010;25:936940.

14. Olson RA, Chhanabhai T, McKenzie M. Feasibility study of the Montreal Cognitive Assessment (MoCA) in patients with brain metastases. Support Care Cancer. 2008;16:1273-1278.

15. Copersino ML, Fals-Stewart W, Fitzmaurice G, Schretlen DJ, Sokoloff J, Weiss RD. Rapid cognitive screening of patients with substance use disorders. Exp Clin Psychopharmacol. 2009;17:337-344. 16. Luis CA, Keegan AP, Mullan M. Cross validation of the Montreal Cognitive Assessment in community dwelling older adults residing in the Southeastern US. Int J Geriatr Psychiatry. 2009;24:197-201. 17. Adler CH, Connor DJ, Hentz JG, et al. Incidental Lewy body disease: clinical comparison to a control cohort. Mov Disord. 2010;25:642-646. 
18. Caviness JN, Driver-Dunckley E, Connor DJ, et al. Defining mild cognitive impairment in Parkinson's disease. Mov Disord.

2007;22:1272-1277. 